\title{
ARTICLE
}

Cite this: DOI: $10.1039 / \times 0 \times x 00000 x$

Received 00th January 2012,

Accepted 00th January 2012

DOI: $10.1039 / \times 0 \times x 00000 x$

www.rsc.org/

\section{Thermoresponsive Magnetic Colloidal Gels via Surface-Initiated Polymerisation from Functional Microparticles.}

\author{
S. A. Braim ${ }^{a}$, K. M. Shakesheff ${ }^{a}$, B. R. Saunders ${ }^{b}$ and C. Alexander ${ }^{a}$
}

Novel magnetothermally responsive core-shell microparticles have been synthesized. The aqueous suspensions of these particles exhibit fast thermoreversible fluid-to-gel transitions and retain good magnetic properties. Rheological measurements demonstrated that the viscoelasticity of the prepared particle gels can be tuned, enabling these gels to have the mechanical properties that should facilitate their applications as 3D cell scaffolds for in vitro expansion of cells. Also, it was found that the responsive particles could be used in repeated heating-cooling cycles without marked changes in gel elasticity. Presto Blue viability assays of 3T3 fibroblasts and human mesenchymal sem cells cultured within the colloidal gel showed that the cells remained viable and proliferated, with significant increases in cell numbers over extended culture times. Confocal microscopy images of 3T3 cells cultured within the colloidal gel demonstrated that cells adhered, spread and retained their normal morphologies during proliferation.. Furthermore, magnetic separation allowed efficient recovery of cells after their expansion in vitro without need for enzyme-mediated release steps. Trypsin-free cell passages were performed allowing multiple growth, separation and reloading of cells within the colloidal gels. Overall, the results suggest this colloidal gel has potential as a 3D scaffold for in vitro expansion of a variety of cell types and for enzyme free cell harvesting.

\section{Introduction}

The emerging field of regenerative medicine is critically dependent on materials to support cell culture, differentiation and proliferation. ${ }^{1-3}$ Colloidal gels derived from reversibly associating microparticles are of potential value in these applications, for example as building blocks for scaffolds which can support tissue growth or as microcarriers for cell delivery. ${ }^{4-}$ 7 In addition, reversibly-assembling colloidal gels might act as substrates on which to grow specific cells and then recover the resulting expanded population of cells following culture without the need to use trypsin during passaging, as the use of trypsin may affect cell phenotype preservation and gene expression. ${ }^{8-}$ ${ }^{10}$ A desirable feature of any material intended for cell culture application is an ability to be dispersed into a mobile suspension below body temperature but also the capacity to form a supportive and stable gel at $>37^{\circ} \mathrm{C}$.

Thermoresponsive polymers have been widely used as surfacemodifiers of micro-and nano-particles to provide such reversibly-associative properties. ${ }^{11-14}$ At temperatures below their phase transition, thermoresponsive polymers attached to the surface of microparticles can provide steric stabilization, overcoming the tendency for interparticle aggregation. This enables the modified microparticles to be used in free-flowing suspensions with cells. Above the phase transition temperature of the attached thermoresponsive polymer, the outer 'corona' of the microparticles collapses, colloidal stability is lost and interparticle association occurs to form a heterogeneous gel. Examples now exist of reversibly-associating particles for growth and support of multiple cell types and for delivery of therapeutic cells. ${ }^{15-17}$ In addition, coupling of thermoresponsive polymers to magnetite-containing microspheres has recently been shown to enhance the culture and expansion of stem cells, and facilitate rapid recovery of the expanded cell population by simple magnetic separation. ${ }^{18}$

The 'switchable' component of reversibly associating colloidal microparticles can be generated by attaching the thermoresponsive polymer either by physical adsorption ${ }^{19,20}$ or chemical grafting. ${ }^{21,} 22$ The most simple method i.e. physical adsorption is rapid and can be adapted to many microparticle surfaces but has the drawback of possible desorption of polymer chains during extended application. The chemical 
grafting method i.e. the formation of covalent bonds between polymer corona and the microparticle core, provides robust and better-defined materials but can be more complex and timeconsuming. Covalent links between surfaces and polymer can be generated either by growing polymers from initiator sites pre-attached at the surface ("grafting from") or by conjugating pre-formed polymers to reactive groups at the particle surface ("grafting to"). ${ }^{23}$ While these approaches provide permanent attachment of responsive polymer to microparticle surface, the "grafting from" technique generally provides denser surface polymer layers. This is because monomers have lower steric demands than polymers and can easily diffuse to initiator and propagation sites during polymerization reactions, thus producing higher grafting density. ${ }^{24}$

A number of controlled polymerization techniques have been used to graft polymer chains on the surface of particles. These include atomic transfer radical polymerization (ATRP), ${ }^{25-27}$ reversible addition fragmentation transfer (RAFT) ${ }^{28}$ and nitroxide mediated polymerization (NMP). ${ }^{29}$ Amongst these methods ATRP is of particular interest for grafting acrylic and methacrylic monomers, as it can be applied in dispersed media with good control over grafting density. ${ }^{30}$

In this study, we describe the synthesis and characterisation of thermoresponsive poly(chloromethylstyrene)-gr- microparticles and their preliminary application for trypsin-free cell culture. PCMS microspheres were chosen as a core functional substrate because the chloromethyl groups on their surface are useful initiator sites for ATRP polymerization, ${ }^{31}$ and because chloromethylstyrene beads are well-established as supports for solid-phase chemistry. ${ }^{32}$ The thermoresponsive component, PDEGMA, was chosen as it is well-tolerated by cells, displays a lower critical solution temperature (LCST 26 ${ }^{\circ} \mathrm{C}$ ) just above ambient temperature but below human body temperature ${ }^{33}$ and has a good resistance to absorption of proteins. ${ }^{34}$ While there have been a number of papers describing thermoresponsive surfaces and gels for cell culture, ${ }^{35}$ there have been relatively few in which microparticles have combined responsive surfaces with magnetic properties ${ }^{36}, 37$ and thus we included also a procedure for incorporation of magnetite nanoparticles. To do this we took advantage of the swellable properties of the lightly-cross-linked polystyrene core to embed stabilized magnetite nanoparticles. This in turn allowed the preparation of a dual magneto-thermally responsive material. The reversible thermogelling behaviour allows formation of particulate gels, which have potential for 3D support structures for tissue culture, while the magnetic nanoparticle components enable simple and rapid separation of the colloidal particles following application (Scheme 1). poly(diethyleneglycolmethylmethacrylate) (PCMS-PDEGMA)
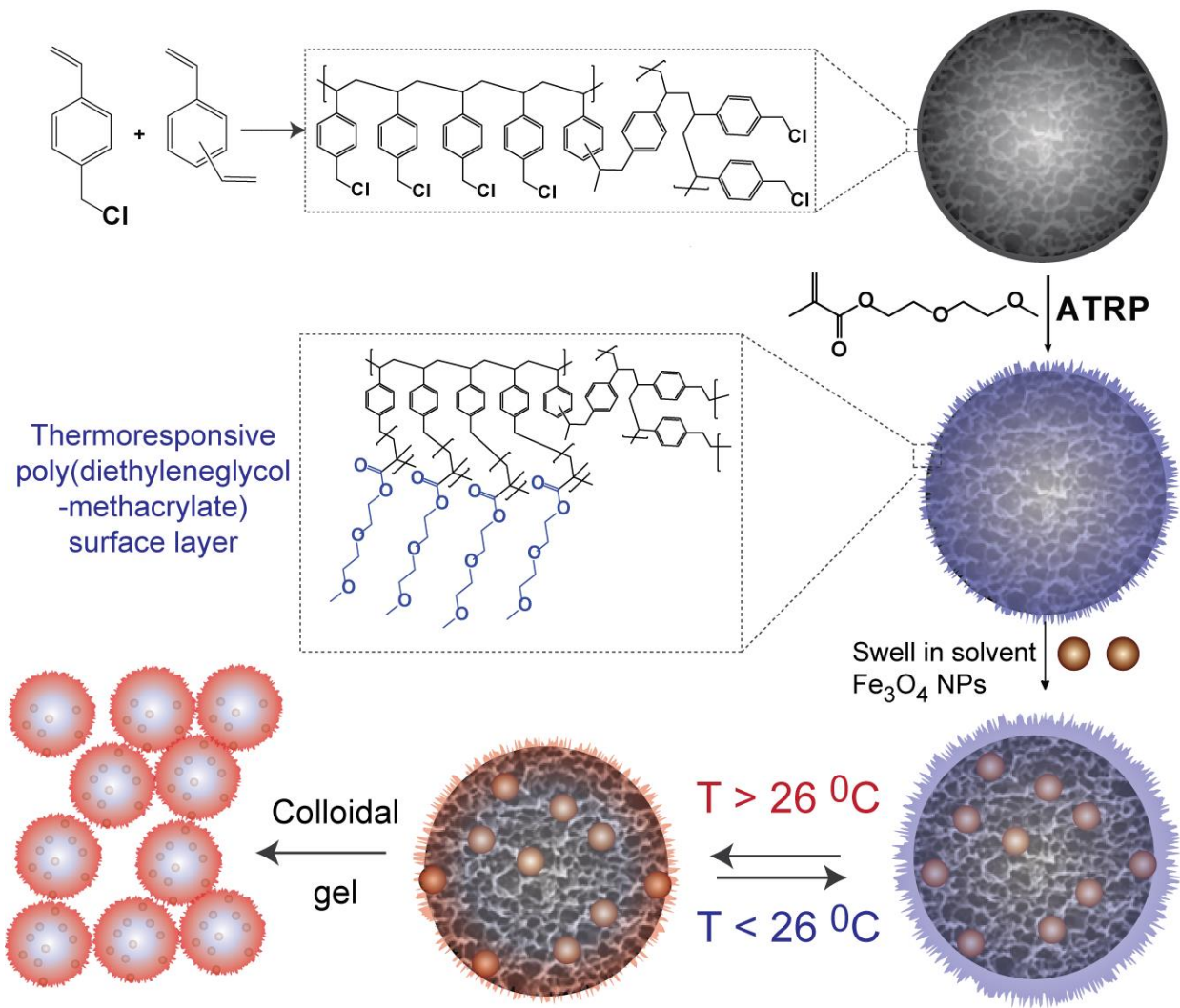

Scheme 1. Synthesis of thermoresponsive magnetic microspheres

\section{Experimental}

Materials and Methods 
Chloromethylstyrene (CMS) and divinylbenzene (DVB) monomers were washed with $5 \%$ sodium hydroxide solution to remove inhibitors before being used. 2,2-Azobisisobutyronitrile (AIBN) was recrystallized from methanol. 2-Methoxyethanol, ethanol. polyacrylic acid (PAA) has average molecular weight $3000 \mathrm{kDa}$.

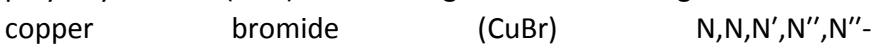
pentamethyldiethylenetriamine (PMDETA), diethyleneglycol methylmethacrylate and all other chemicals were bought from Sigma-Aldrich Company Ltd. UK and used as received. Red Fluorescent Protein expressing NIH-3T3 mouse embryonic fibroblasts (RFP-3T3s) and Human Bone marrow-derived mesenchymal stem cells (hMSCs) were obtained from $\mathrm{Dr}$ James Dixon (School of Pharmacy, University of Nottingham) following transfection of original cell lines from LGC Standards (Middlesex, UK) and the JCRB Cell Bank (Japan) to incorporate fluorescent proteins.

\section{Synthesis of poly(chloromethylstyrene) microspheres}

Poly(chloromethylstyrene) microspheres were synthesised by dispersion polymerization. In a typical procedure, poly(acrylic acid) $0.30 \mathrm{~g}(0.0001 \mathrm{mmol}, \mathrm{M} . \mathrm{W}=3000 \mathrm{kDa})$ was dissolved in a mixture of ethanol $(13 \mathrm{~mL})$ and 2-methoxyethanol $(1 \mathrm{~mL})$, placed in a polymerization reactor. Next, AIBN $(0.02 \mathrm{~g}, 0.12$ $\mathrm{mmol}), \mathrm{CMS}$ monomer (1.52 g, $10 \mathrm{mmol})$, and DVB (0.076 g, 0.5 $\mathrm{mmol}$ ) were added to the above solution. The resulting solution was sonicated for 1 minute within an ultrasonic water bath for the complete dissolution of AIBN in the polymerization medium. Then, the solution was degassed with nitrogen for 5 minutes. The reactor was sealed and placed into a shaking water bath $(120 \mathrm{cpm})$ at $70^{\circ} \mathrm{C}$ and maintained at this temperature for $24 \mathrm{~h}$ to complete the polymerization. The reactor contents were cooled to room temperature and the resulting particles were separated by centrifugation. Precipitated particles were washed with ethanol $(3 \times 100 \mathrm{~mL})$ and water $(2 \times 100 \mathrm{~mL})$ and lyophilised.

\section{General procedure for synthesis of magnetite nanoparticles}

Magnetite $\left(\mathrm{Fe}_{3} \mathrm{O}_{4}\right)$ nanoparticles were obtained by a chemical co-precipitation method as described elsewhere ${ }^{38,39}$ with some modification. $\mathrm{FeCl}_{3} \cdot 6 \mathrm{H}_{2} \mathrm{O}\left(3.65 \mathrm{~g}, 13.5 \mathrm{mmol}\right.$ ) and $\mathrm{FeCl}_{2} \cdot 4 \mathrm{H}_{2} \mathrm{O}$ $(1.34 \mathrm{~g}, 6.75 \mathrm{mmol})$ were dissolved in water $(10 \mathrm{~mL})$ which had been deoxygenated by bubbling with nitrogen gas. The temperature of the solution was elevated to $80^{\circ} \mathrm{C}$ and heating continued for $0.5 \mathrm{~h}$. To this solution, $12.5 \mathrm{ml}$ of $25 \%$ ammonia solution was added at $80{ }^{\circ} \mathrm{C}$ with continuous stirring. After 30 min sodium oleate $(1.5 \mathrm{~g}, 5 \mathrm{mmol})$ was added to stabilise produced magnetite nanoparticles. The solution was cooled to room temp and the precipitate was isolated by magnetic separation and washed several times with distilled water. The sizes and morphologies of the obtained nanoparticles were determined by transmission electron microscopy.

\section{Preparation of magnetic PCMS-PDEGMA microspheres}

Magnetic polymer microspheres were prepared by a swelling and solvent evaporation process. Polymer microspheres (1.0 g) were swollen by immersion in chloroform, and then dispersed magnetic nanoparticles $(150 \mathrm{mg}$ ) in chloroform were added to the above suspension. The final mixture was shaken for 24 hours to allow the magnetite nanoparticles to enter the swollen polymer microspheres. After this time, the temperature of the solution was increased and the chloroform was evaporated slowly under reduced pressure, enabling the magnetite nanoparticles to be retained inside the microspheres. The resulting magnetite-impregnated microspheres were precipitated by addition of petroleum ether and separated by centrifugation. The final microparticles were washed with ethanol then with distilled water before being lyophilised.

Surface initiated atomic transfer radical polymerization (SI-ATRP) for grafting of PDEGMA on PCMS microspheres.

A round-bottom flask was charged with poly(chloromethylstyrene) microparticles (1.2 g, $1.45 \mathrm{mmol})$, and DEGMA (13.6 g, $72.5 \mathrm{mmol}, 27.3 \mathrm{~g}, 145 \mathrm{mmol}$ ) or $41 \mathrm{~g}, 217.5$ $\mathrm{mmol})$, dependent on the desired monomer:initiator ratio, $\mathrm{CuBr}$ (0.2 g, $1.45 \mathrm{mmol})$, PMDETA (0.25 g, $1.45 \mathrm{mmol})$ and cyclohexanone $(5 \mathrm{ml})$. The flask was then degased with argon for 30 minutes. The mmol ratios of initiator: CuBr: PMDETA: monomer were 1: 1: 1: 50 or 100 or 150, respectively. The solution was stirred as the temperature was increased to $80^{\circ} \mathrm{C}$ and maintained at this temperature for $24 \mathrm{~h}$ to run the polymerisation. The produced PCMS-PDEGMA particles were separated by centrifugation and washed three times with THF to remove any non-surface-bound polymers produced during the polymerization reaction. The surface-grafted particles were washed repeatedly with EDTA solution to remove any residual copper. After two further water washes, the microparticles were lyophilised and stored.

\section{Synthesis of linear thermoresponsive 'control' polymer}

Poly(diethylenglycolmethacrylate) (PDEGMA) was prepared by conventional free radical polymerization to act as a 'control' polymer for surface adsorption to microparticles in accord with our previous protocols. ${ }^{18}$ Diethyleneglycolmethaacrylate (11 g, $59 \mathrm{mmol})$ was weighed into a round bottom flask and 1dodecanethiol $(0.08 \mathrm{~g}, 0.4 \mathrm{mmol})$ and $20 \mathrm{ml}$ of 2-butanone were added. AIBN (0.07 g, $0.4 \mathrm{mmol})$ was added and the mixture was degassed with nitrogen for 25 minutes. The solution temperature was elevated to $70{ }^{\circ} \mathrm{C}$ and polymerization was performed at that temperature for $1 \mathrm{~h}$. The reaction was then stopped by cooling the reaction vessel to $0^{\circ} \mathrm{C}$ and opening the contents to air. The polymer was precipitated and excess monomers were removed by cycles of precipitation of polymer from 2-btanone into hexane (polymer solution to hexane 1:10). Polymer properties $\left(M_{\mathrm{w}}, M_{\mathrm{n}}\right)$, and polydispersity $(\bigoplus)$ were determined by GPC compared to polystyrene standards: $M_{\mathrm{w}}=$ $50.3 \mathrm{kDa}, M_{\mathrm{n}}=28 \mathrm{kDa}, \oplus=1.8$. NMR data matched those of prior preparations of this material. ${ }^{18}$

\section{Preparation of thermoresponsive suspensions}

All suspensions studied were obtained by dispersing different concentrations $(\% \mathrm{w} / \mathrm{v})$ of microspheres in cell culture medium 
(DMEM) or in distilled water, then the suspension were subjected to frequent votex mixing.

\section{Characterization Techniques}

\section{Scanning Electron Microscopy (SEM)}

SEM was used to measure the average size, particle size distribution and surface morphology. Samples were prepared by spreading a suspension of particles on an aluminium stub coated with the carbon tape. The samples were dried and then coated with a thin layer of gold (Blazer SCD030 Sputter coater, Blazer Union Ltd, Liechtenstein) for $180 \mathrm{sec}$. the images were viewed with a JEOL 6060V (JEOL Ltd, UK), an accelerating voltage of $30 \mathrm{kV}$ was used. The number average diameter $\left(D_{\mathrm{n}}\right)$, standard deviation (SD) and coefficient of variation CV (\%) was calculated by measuring at least 100 particles from different areas of the sample.

\section{Transmission Electron Microscopy (TEM)}

The morphologies and sizes of synthesized particles were examined by using transmission electron microscopy (TEM - FEI Tecnai) at an acceleration voltage of $100 \mathrm{kV}$. Samples were prepared by placing drops of diluted particle suspensions in water on the surface of a copper mesh grid, and then drying the particles in air at room temperature prior to examination.

\section{Time-of-Flight Secondary Ion Mass Spectrometry (ToF-SIMS)}

Analyses were performed using a ToF-SIMS IV instrument (IONTOF GmbH, Münster, Germany) equipped with a bismuth liquid metal ion gun and a single-stage reflection analyser. Dry powder samples were adhered to double-sided tape to produce an immobile surface suitable for the instrument. Typical operating conditions utilized a $\mathrm{Bi}^{3+}$ primary ion energy of $25 \mathrm{kV}$ and a pulsed target current of approximately $1.0 \mathrm{pA}$. . Data in the negative and positive secondary ion polarities were collected and analysed using Surface Lab 6 (ION-TOF Gmbh, Münster, Germany).

\section{X-Ray Photoelectron Spectroscopy}

X-ray photoelectron spectroscopy analysis was performed using a Kratos Axis Ultra spectrometer (Kratos Analytic Ltd, UK) equipped with a monochromated X-ray source (1486.6 eV), at $15 \mathrm{~mA}$ emission current and $10 \mathrm{kV}$ anode potential. Dry powder samples were adhered to double side tape. The instrument was operated at fixed transmission mode. Data analyses were carried out using CASAXPS software (version 2.3.16) (Casa software Itd, Teignmouth, United Kingdom). All scans were charge corrected to $\mathrm{C} 1 \mathrm{~s}$ at $284 \mathrm{eV}$.

\section{ATR- FTIR characterization}

FTIR spectra of the PCMSt and surface-grafted particles were recorded in the range of $4000-400 \mathrm{~cm}^{-1}$ on a BioRad FTS 6000 FTIR Spectrometer, equipped with an attenuated total reflectance (ATR) accessory providing an analysis of the sample surface. Particle powders were loaded directly onto the ATR surface for analysis: DTGS optics at $5 \mathrm{KHz}$ and $4 \mathrm{~cm}^{-1}$ resolution were used.

\section{Temperature dependent turbidity measurement}

A Beckman Coulter DU 800 UV spectrophotometer with a thermostat was used for measuring the change of absorption of dilute suspensions of particles over a temperature range of 10$50{ }^{\circ} \mathrm{C}$. The temperature was controlled and measured using a peltier plate heating system (Beckman) and was increased at a rate of $1{ }^{\circ} \mathrm{C} \mathrm{min}-1$. Absorbances of the samples were measured at a wavelength of $550 \mathrm{~nm}$.

\section{Tube Inversion test}

Typically $1 \mathrm{ml}$ of aqueous polymer microparticle suspension was added to a $7 \mathrm{ml}$ glass vial. The sample was adjusted to the desired temperature $\left(37^{\circ} \mathrm{C}\right)$ for 2 minutes in a thermostat water bath. The mobility of the dispersions was assessed by inverting the vial. If the suspension had not flowed after 10 seconds it was considered to be a self-supporting gel.

\section{Rheometry characterizations}

The rheological measurements were performed using an Anton Paar Physica Rheometer, equipped with parallel plate geometry (25 mm diameter) and the gap distance between two plates was set as $0.5 \mathrm{~mm}$. Rheoplus Software (Version: 3.6x) was used for analysing data.

Strain sweep tests were performed by using a fresh aliquot of sample. The sample was left in between the plates for $5 \mathrm{~min}$ at $37^{\circ} \mathrm{C}$ before running the strain sweep test. Strain sweeps were carried out between $0.01 \%$ and $100 \%$ strain at an angular frequency of $1 \mathrm{rad} \mathrm{s}^{-1}$ and at a temperature of $37^{\circ} \mathrm{C}$.

Temperature ramp experiments were recorded at $0.05 \%$ strain at a frequency of $1 \mathrm{rad} \mathrm{s}^{-1}$ with a heating rate of $1^{\circ} \mathrm{C} / \mathrm{min}$ from $10^{\circ} \mathrm{C}$ to $40^{\circ} \mathrm{C}$. Before running the experiment, the lower plate and the upper parallel plate $25 \mathrm{~mm}$ (PP25) were left in contact for $5 \mathrm{~min}$ at $10^{\circ} \mathrm{C}$. Afterwards, $300 \mu$ of sample was applied on the lower plate. The sample was equilibrated at the desired temperature $\left(10^{\circ} \mathrm{C}\right)$ for $4 \mathrm{~min}$ before starting the run. The tests were all performed using fresh aliquots of sample.

Frequency Sweeps were performed at $37^{\circ} \mathrm{C}$ between 0.1 and $100 \mathrm{rad} \mathrm{s}^{-1}$ at a strain value of $0.05 \%$. Before running the experiment, the PP25 and the lower plate were left in contact at $37^{\circ} \mathrm{C}$ for $5 \mathrm{~min}$. Then, $300 \mu \mathrm{l}$ of sample was applied on the lower plate. The sample was equilibrated at the desired temperature $\left(37^{\circ} \mathrm{C}\right)$ for $5 \mathrm{~min}$ before starting the run.

\section{Cell Culture}

3T3 fibroblast cells and immortalised human mesenchymal stem cells (ihMSCs) were cultured in Complete Medium which consists of Dulbecco's Modified Eagle Medium (DMEM)(Gibco, UK) supplemented with $10 \%$ Foetal bovine serum (FBS), 1\% antibiotic/antimycotic solution, 1\% L-glutamine (2 mM) and 1\% non-essential amino acids (Sigma-Aldrich, UK). Red fluorescent protein 3T3 cells (RFP-3T3) were derived and cultured as 
described elsewhere. ${ }^{40}$ All cells were maintained in a humidified tissue-culture incubator at $37{ }^{\circ} \mathrm{C}$ and with $5 \% \mathrm{CO}_{2}$.

\section{Material sterilisation}

All materials were sterilised before contact with cells through exposure to UV light at $280 \mathrm{~nm}$ for 60 minutes in a class II microbiology safety cabinet.

\section{Cell encapsulation and three dimentional cell culture within the Colloidal Gels}

The particle gels used in the cell culture experiments were formulated to contain $30 \% \mathrm{w} / \mathrm{v}$ microparticles. Aliquots of microparticle suspensions $(300 \mu \mathrm{l})$ in Complete Medium were added to 24-well culture plates. While still fluid, Complete Medium $(20 \mu \mathrm{l})$ containing approximately $1 \times 10^{5}$ of 3T3 or MSC cells was added with mixing. The plates were then placed in an incubator at $37^{\circ} \mathrm{C}$ for 10 minutes to obtain individual particulate gels within which the cells were encapsulated. Further complete medium $(300 \mu \mathrm{l})$ was added on top of the gelled suspensions and the plates were incubated at $37{ }^{\circ} \mathrm{C}$ until further experiments, imaging or viability assays were carried out. The cell nutrient medium was changed every $48 \mathrm{hr}$. The PrestoBlue assay was used to assess cell viability and proliferation, following the manufacturer's instructions (Invitrogen, UK) with some modification to correct for background fluorescence. A standard calibration curve was used to determine the total number of viable cells.

Trypsin-free cell recovery via magnetic mell separation and cell passages

Firstly, the cell-seeded colloidal gels were liquefied by cooling to $10^{\circ} \mathrm{C}$ to release the cells, and the obtained suspensions were diluted in media. Next, the mixtures were transferred to a glass tube and the colloidal particles were separated using a magnetic bar while the cells remained suspended in media. The cell suspension was mixed and the magnetic separation step was repeated three times in order to remove completely the magnetic particles. The separated suspension was then centrifuged, and the pellet was resuspended and seeded into tissue culture flasks. The cells were incubated at $37 \mathrm{C}$ for 3 hours in the tissue culture flasks to permit cells to adhere. Finally, a Presto Blue viability assay was performed to quantify the cell recovery.

\section{Statistical analysis}

GraphPad Prism analysis software (Version 6) was used for Statistical analysis. Differences among groups were determined by One-way ANOVA Multiple Comparisons Test and the different were considered to be significant if $p<0.05$.

\section{Confocal microscopy cell imaging}

RFP -3T3 cells cultured within particle gels were imaged using Confocal Laser Scanning Microscopy (CLSM). A Zeiss LSM 510 Meta laser scanning confocal microscope, equipped with a 543 $\mathrm{nm}$ HeNe laser was used. Images were taken at 10x and 40x magnification.

\section{Live/Dead cell viability assay}

A Live/Dead cell viability/cytotoxicity assay (Molecular Probes) was used for evaluating the viability of encapsulated cells within the colloidal. The double colour fluorescent staining assay was performed following the manufacturer's instructions on days 5 and 10. Stained cells were imaged using a confocal laser scanning microscope (Leica TCS SPE Macro-Confocal) with appropriate filter sets. Live cells displayed bright green fluorescence (calcein AM), whereas dead cells fluoresced red (ethidium homodimer-1).

\section{Results and discussion}

\section{Microscopy analysis}

Dispersion polymer synthesis generated PCMS microspheres of uniform size and morphology as shown by Scanning Electron Microscopy (SEM) and Transmission Electron Microscopy (TEM). As apparent from the micrographs, PCMS microspheres (Figure 1, top row) were smooth and spherical, with a diameter of $1.3 \mu \mathrm{m}$ (Coefficient of Variance CV 5.4\%). The surface ATRP procedure generated PCMS-PDEGMA microparticles with increasing size and surface roughness (Figure 1 rows 2-4). The average particle diameter of PCMS increased after grafting the PDEGMA from accessible chloromethyl residues. These diameter were $1.6 \mu \mathrm{m}$ (CV 6.1\%), $1.8 \mu \mathrm{m}$ (CV 6.5\%) and $2.1 \mu \mathrm{m}$ (CV $7.2 \%$ ) for $1: 50,1: 110$ and $1: 150$ initiator: monomer ratios used during grafting process, respectively. Thus, the particle diameters were increased as the initiator: monomer ratios were increased. In addition, surface roughness of the microspheres increased with monomer:initiator ratio, indicative of a controlled polymerisation route. Transmission electron microscopy (TEM) enabled visualisation of the grafted PDEGMA regions on and in the surface of microparticles, observed as diffuse regions in the micrographs because the brush layer was likely to be less compact compared to the core PCMS (Figure 1 c and d). 


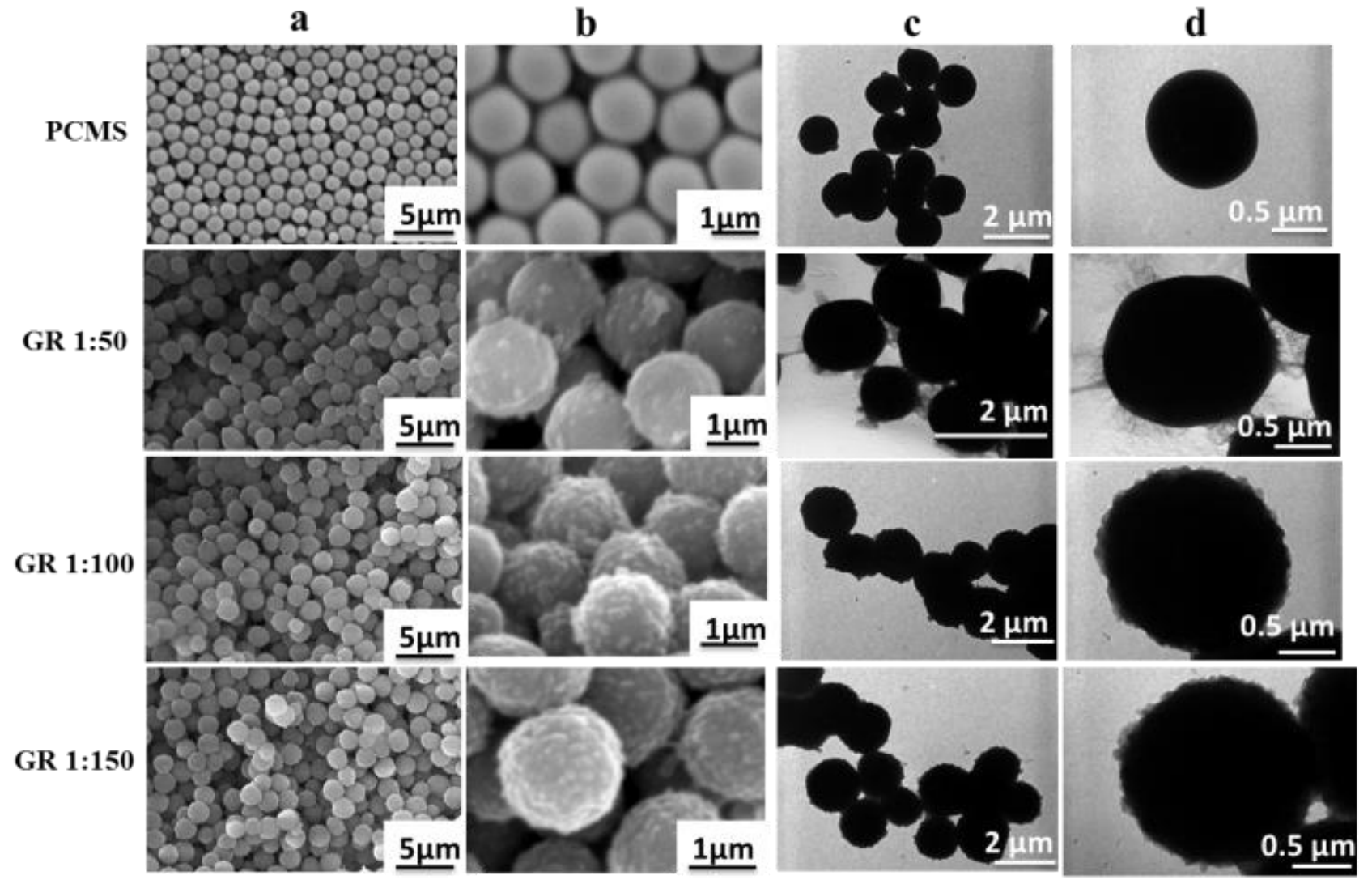

Figure 1: Representative (a) and (b) scanning electron micrographs at low and high magnification of PCMS microparticles that shows smooth spherical shape and PCMS-PDEGMA microparticles produced with different initiator: monomer loading during grafting reaction (1:50, 1:100, and 1:150). (c) and (d) Transmission electron micrographs at low and high magnification of the same samples. After grafting, the particle diameter and surface roughness increased in line with monomer concentration during the surface ATRP reaction.

\section{Surface characterisation}

A number of surface sensitive characterization experiments (ATR-FTIR, XPS, ToF-SIMS) were performed to identify chloromethyl groups on the surface of PCMS, necessary for initiating ATRP reactions, and to confirm the presence of grafted PDEGMA. The ATR-FTIR spectrum of PCMS (Figure S1a ESI) showed two characteristic absorption bands at 672 and 1263 $\mathrm{cm}^{-1}$, attributed to the $\mathrm{C}-\mathrm{H}$ bending vibrations in chloromethyl groups and stretching vibrations of $\mathrm{C}-\mathrm{Cl}$, respectively. However, the spectrum of PCMS-PDEGMA (Figure S1b ESI) showed two new distinct absorptions at $1105 \mathrm{~cm}^{-1}$ and $1725 \mathrm{~cm}^{-1}$ which could be attributed to $\mathrm{C}=\mathrm{O}$ and $\mathrm{C}-\mathrm{O}$ stretching vibrations from carboxylic groups of PDEGMA, respectively. It was also observed that the absorption bands for the chloromethyl group were reduced in intensity for the PCMS-PDEGMA beads. Moreover, XPS spectra of PCMS (Figure S2 ESI) displayed emission peaks at 535, 284, and $200 \mathrm{eV}$, assigned to transitions of $\mathrm{O} 1 \mathrm{~s}, \mathrm{C} 1 \mathrm{~s}$, and $\mathrm{Cl} 2 \mathrm{p}$ electrons, respectively. However, after grafting PDEGMA (Figure S2 b ESI) the percentage of oxygen increased and percentage of $\mathrm{C} 1 \mathrm{~s}$ decreased and $\mathrm{Cl} 2 \mathrm{p}$ disappeared. High resolution carbon spectra (Figure S2c and d ESI) showed a sharp increase in the proportion of methoxy groups corresponding to PDEGMA side-chain termini after grafting. Furthermore, Time-of-flight secondary ion mass spectroscopy (ToF-SIMS) was performed as a complementary characterisation technique to the XPS and ATR-FTIR analyses. ToF-SIMS overlaid spectra (Fig. S3 ESI) indicated the presence of initiator groups in PCMS via the mass peaks at $35 \mathrm{~m} / \mathrm{z}$ corresponding to the characteristic negative fragment ions of chlorine atoms. However, in the surface-grafted particles, the intensities of chlorine bands were decreased with increasing intensity of $\mathrm{CH}_{3} \mathrm{O}^{-}$(methoxy group in PDEGMA) components.

\section{Thermal analysis}

The extent of surface modification was quantified by thermogravimetric analysis (TGA) of linear PDEGMA polymer, PCMS particles and PCMS-PDEGMA particles (Figure S4 ESI). The PDEGMA thermogram showed a single step weight loss of $100 \%$ between 200 and $380{ }^{\circ} \mathrm{C}$. By comparison. PCMS particles exhibited two stages of decomposition, with the bulk of the polymer degraded between 400 and $500{ }^{\circ} \mathrm{C}$, with a second lower loss stage from $\sim 800$ to $1000{ }^{\circ} \mathrm{C}$. However, the PCMSPDEGMA particles exhibited at least three transitions with temperature. A small weight loss occurring at $100{ }^{\circ} \mathrm{C}$ was attributable to evaporation of water from the partly hydrated PDEGMA chains, and a second loss stage between $200{ }^{\circ} \mathrm{C}$ and $380{ }^{\circ} \mathrm{C}$ corresponded to decomposition of PDEGMA grafted on 
the surface of microspheres. The extent of weight loss for the second stage was 15\%, indicating the likely maximum of PDEGMA composition relative to the PCMS core. Further decomposition followed the same pattern observed for the PCMS microparticles, indicating also that the microparticles were composed of two distinct polymer types. However, at temperatures above $800{ }^{\circ} \mathrm{C}$ no more weight loss occurred in the case of PCMS-PDEGMA and around $15 \mathrm{wt} \%$ residue remained, which may be attributed to the mass of $\mathrm{Fe}_{3} \mathrm{O}_{4}$ nanoparticles loaded into the microspherse

We predicted that PDEGMA would grow from all accessible sites in the PCMS beads, as the microparticles were expected to be macroporous owing to their low degree of coss-linking and synthesis in polar solvents The increase in overall size and roughness following grafting (Figure 1 ) appeared to confirm this prediction. However, we also expected a surface layer of PDEGMA to be present, which would endow the microparticles with thermoresponsive properties in aqueous suspensions. Thus we predicted that PCMS-PDEGMA microparticles would reversibly aggregate from water-based suspensions dependent on temperature whereas PCMS beads would not disperse irrespective of temperature. UV/ Visible spectroscopy was used to confirm thermoresposive particle aggregation by measuring the temperature dependent turbidity of dilute suspensions of PCMS and grafted particles over the temperature range from 10 to $60{ }^{\circ} \mathrm{C}$. Suspensions of PDEGMA-grafted particles showed a marked decrease in turbidity from $20-40{ }^{\circ} \mathrm{C}$ whereas the ungrafted PCMS microsphere suspensions did not change in turbidity over this temperature range (Figure S5 ESI). A decrease in the absorbance with increase of temperature above the cloud point (as an approximation of the Lower Critical Solution temperature or LCST) of the free polymer is indicative of pronounced aggregation. The critical flocculation temperature (CFT) was taken as the onset of the decrease in absorbance as the temperature were increased, this was found to be $\sim 22{ }^{\circ} \mathrm{C}$ for grafted particles which is very close to the cloud point of free
PpDEGMA polymer solution. Beyond this temperature the dispersions revealed intrinsic aggregation upon heating which was observed by rapid decrease in absorbance. Below the phase transition temperature the PDEGMA brushes were chain extended on the surface of particles, thus stabilizing the particles but above the critical temperature the PDEGMA chains were collapsed leading to particle aggregation. These data indicated that growth of PDEGMA polymers from the chloromethylstyrene residues was successful and resulted in an outer layer of thermoresponsive polymer on the microparticles.

Swelling of the microparticles in a good solvent for polystyrene $\left(\mathrm{CHCl}_{3}\right)$ enabled encapsulation of magnetite nanoparticles. The average sizes of the prepared magnetite nanoparticles were $\sim 10 \mathrm{~nm}$ (Figure S7 ESI) Loading of the oleate coated magnetite nanoparticles was confirmed by TGA analysis (Figure S4 ESI) and magnetic response (Figure S6 ESI) Typically magnetite-loaded microspheres could be separated from suspensions within 2 minutes. Further TEM characterization (Figure S7 ESI) confirmed the penetration of magnetite nanoparticles into the microspheres.

\section{Colloidal gel evaluations}

Temperature-mediated colloidal fluid-gel transitions were investigated initially by simple tube inversion tests. Images for these assays are presented in Figure 2 and a summary of the data are appended in Table S1 ESI. The suspensions showed thermoreversible association when the concentrations of particles were between 20-35\% (weight/volume) for PCMSPDEGMA, but for $20 \%$ the inter-bead associations were weak and did not form a solid-like gel. Also, magnetic PCMS-PDEGMA particles formed structures which were stable to tube inversion (i.e. remained in the gel state) when the particle concentrations were between $25-35 \%$. In contrast, suspensions prepared with PCMS particles did not show thermoreversible self-association over any range of concentrations. 

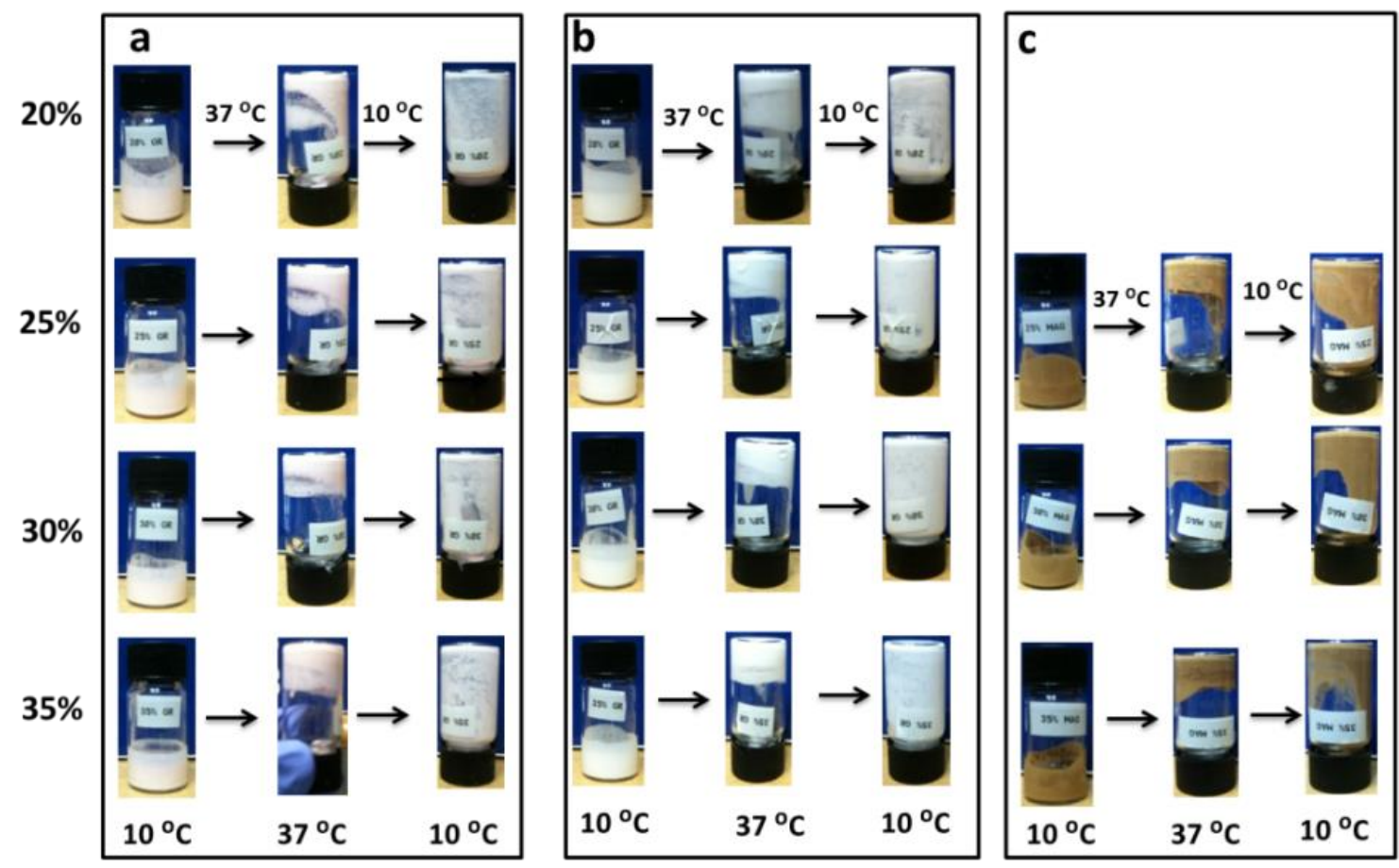

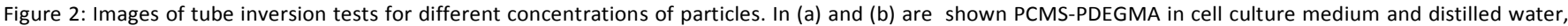
respectively. In (c) magnetic PCMS-PDEGMA microparticles are shown in cell culture medium. Glass vial capacity $7 \mathrm{ml}$ (Height $4.2 \mathrm{~cm}$, Diameter $2 \mathrm{~cm}$ ).

\section{Rheological studies}

The mechanical properties of magnetothermally responsive particulate suspensions/gels at different concentrations were investigated by rheometry. The data from dynamic oscillatory strain sweep, temperature sweep and frequency sweep experiments are shown in Figure 3. Temperature ramp tests were performed to study the temperature dependent viscoelastic properties of aqueous suspensions made from PCMS and PCMS-PDEGMA. All the suspensions of the PCMSPDEGMA particles displayed a temperature dependence of the storage modulus $\left(\mathrm{G}^{\prime}\right)$ above $20^{\circ} \mathrm{C}$. In contrast, suspensions prepared from PCMS particles did not show any temperature dependent elastic modulus within the same temperature range. The elastic modulus was temperature-independent up to around $20{ }^{\circ} \mathrm{C}$ for suspensions prepared with a particle concentration of $25 \%$, but a rapid increase in $\mathrm{G}^{\prime}$ was observed above this temperature. This increase of $\mathrm{G}^{\prime}$ appeared to shift to slightly higher temperatures as particle concentrations increased. The overall increase of $G^{\prime}$ for $35 \%$ particle suspensions was much lower than that of the sample at a concentration of $30 \%$.. This suggested that, at the higher concentration (35\%), the network was formed of a larger number of elastically active links that resulted in larger maximum values. The gel-like structure thus became more persistent as the temperature increased, likely a consequence of increased (and stronger) contacts between 'crowded' microspheres, providing enhanced opportunity for attractive inter-particle associations. The PEGDMA-PEGDMA interactions at the surface changed from repulsive to attractive above the
LCST which provided additional attraction to the interparticle bonds that were present. Also, temperature sweep tests (figure 3c) showed reversible gelation and flow, as demonstrated through increased $\mathrm{G}^{\prime}$ values upon heating, and reduced $\mathrm{G}^{\prime}$ upon cooling. Furthermore, consecutive heating/cooling cycles of a suspension containing $30 \%$ particles (figure $3 \mathrm{~d}$ ) confirmed their temperature response behaviour through multiple increase and decrease of $G^{\prime}$ values with raising and lowering the temperature, respectively.

Strain sweep tests were performed in order to identify the linear viscoelastic region (LVR), which is the range where $G^{\prime}$ is independent of strain. Beyond this region the breakdown of the gel structure was apparent from the rapid decline of $G^{\prime}$ at larger deformations. The gels transformed into liquid-like materials at the critical strain point $(\tan \delta=1)$. It was observed that the LVR was dependent on the particle concentration. For all concentrations at low strains (less than 0.5\%), $G^{\prime}$ was independent of the applied strain, suggesting the gels remained in the linear viscoelastic regime. For (25\%), the linear viscoelastic region extended up to strain values around $1 \%$. This value decreased proportionally with increased particle concentrations, most likely due to increases in the solid particle content that made the gel more fragile and less viscous.

The frequency sweep analysis indicated that the $G^{\prime}$ values were independent of frequency over the entire range for all particle concentrations that were studied. The $\tan \delta$ values of all examined samples were much lower than 1 (i.e. storage modulus $G^{\prime}>$ loss modulus $G^{\prime \prime}$, typical of gel state). It was also observed that $G^{\prime}$ values increased, denoting a higher elasticity 
gel, at higher sweep frequencies. Increases in the particle concentration resulted in higher values of $\mathrm{G}^{\prime}$ while the value of $\tan \delta$ did not show any marked change. The fact that the $\tan \delta$ values were less than 1.0 at room temperature (Fig. $3 \mathrm{~b}$ ) shows that the dispersions were gels at this point but there were weak inter-particle bonds present and these become strengthened at higher temperature. The low $G^{\prime}$ values accounted for the flow observed in the tube inversion tests at room temperature (Fig. 2 ). Under these conditions the microparticle suspensions were weak gels, which became fluid particle suspension on the application of shear. The low overall magnitude of the $G^{\prime}$ values, for these systems was postulated to arise from the particle network consisting of aggregated micrometer-sized particles. In effect, each particle could be considered as a macro-crosslinker with weak chain-chain associative interactions via the collapsed PDEGMA layer above the polymer LCST. Attractive van der Waals interactions between the particles would also have been contributors to particle aggregation. Accordingly, the particle gel modulus increased as the number and density of linkages between the particles increased, but for the micrometer-sized particles in this study the number of interparticle contacts was relatively low (compared to sub-micrometer particles) due to the lower surface area-to-volume ratio. Hence, $G^{\prime}$ values associated with weak gels ( $1000 \mathrm{~Pa}$ ) were not unexpected for these colloidal systems due to the lowr number of (physical) crosslinks per unit volume, and were in agreement with prior reports of related colloidal gels. ${ }^{19}$
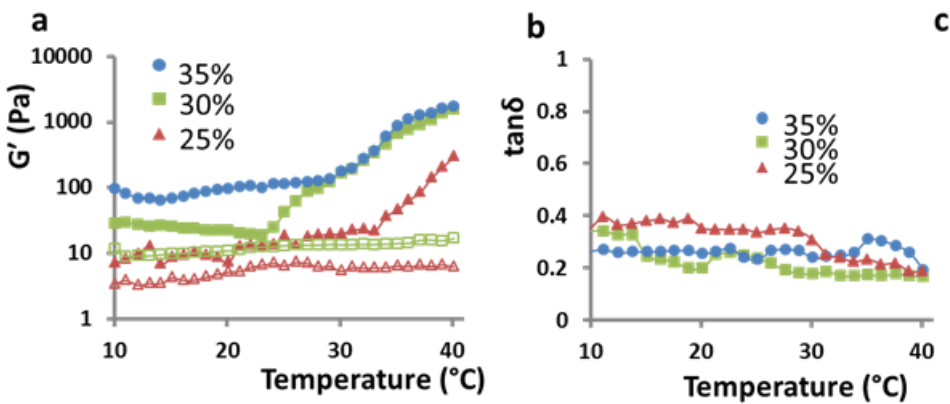

C

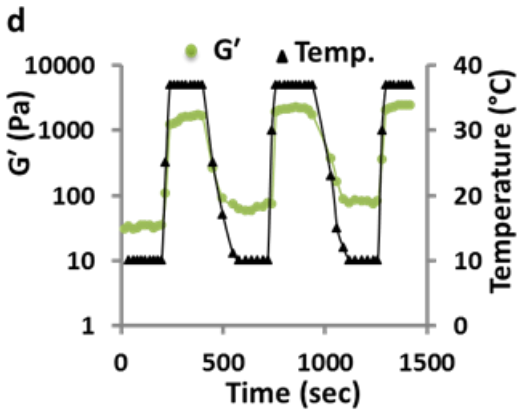

e
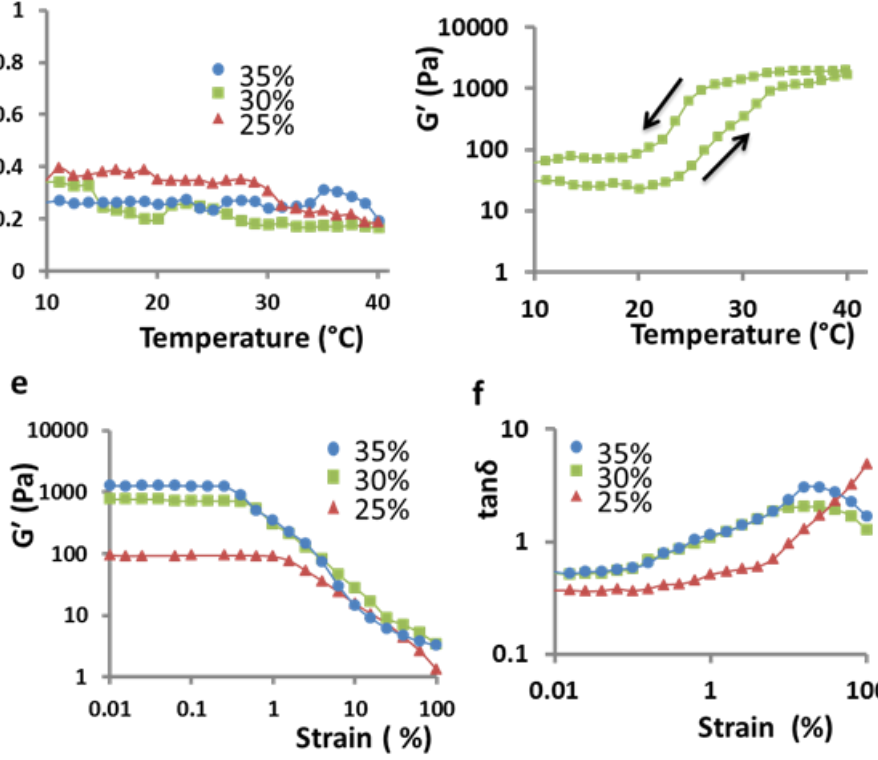

f
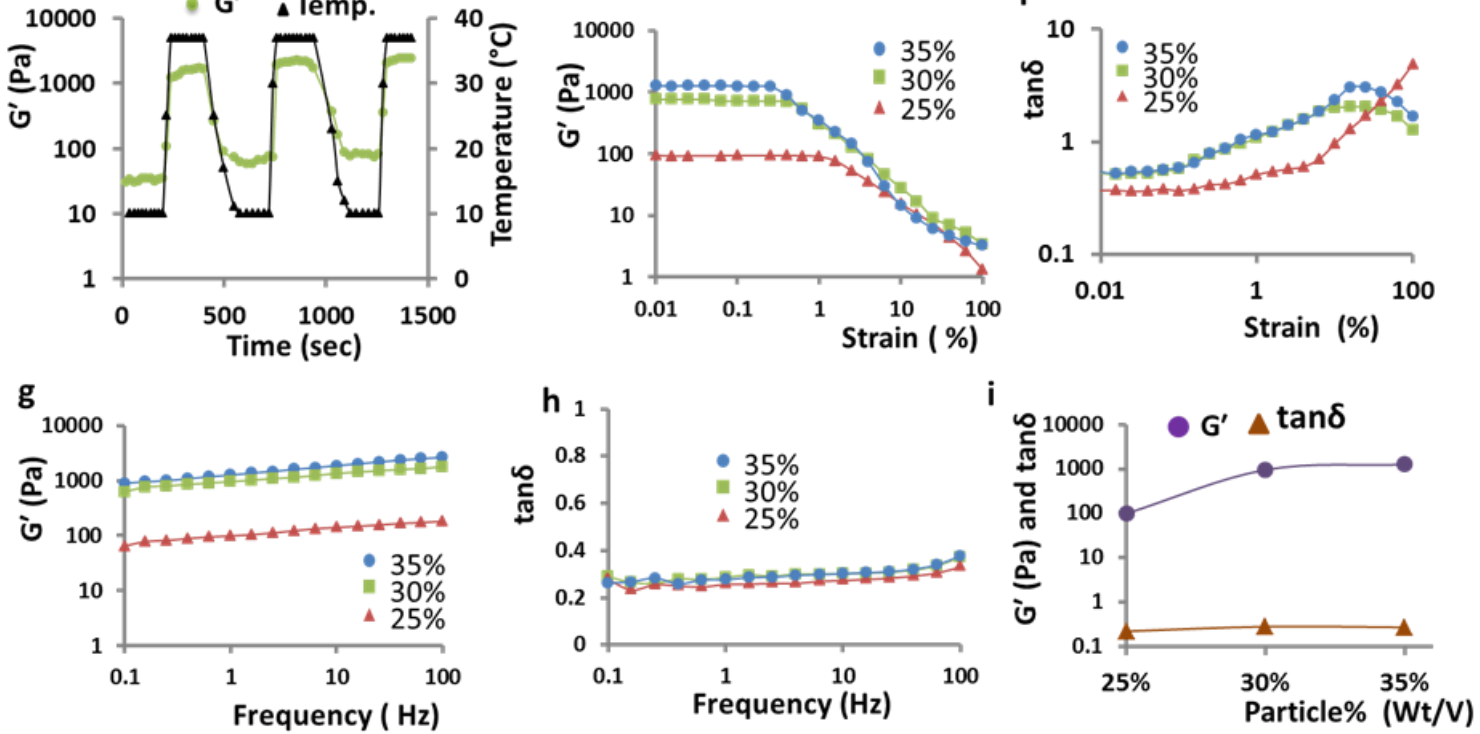

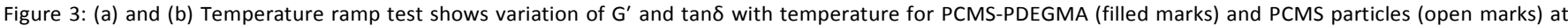

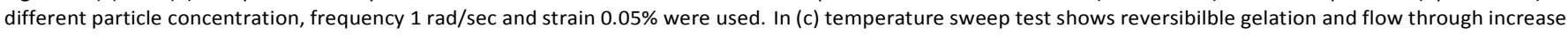

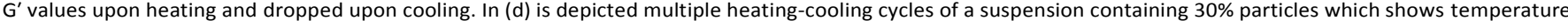

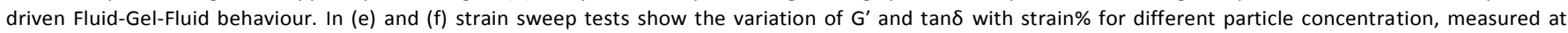

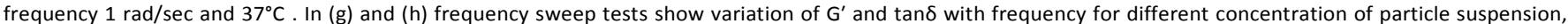
strain $0.05 \%$ and temperature $37^{\circ} \mathrm{C}$ were used during measurments; (i) the variation of $\mathrm{G}^{\prime}$ and tan $\delta$ with particle concentration.

Application of thermoresponsive magnetic colloidal gels to 3D cell culture

A number of assays were carried out to evaluate the potential of the colloidal gels to be used in cell culture. Previous data had shown that
PDEGMA adsorbed onto polystyrene-DVB microparticles with magnetic cores did not lead to any cytotoxicity in fibroblasts or stem cells. ${ }^{18}$ Cell adhesion, distribution, viability and proliferation were thus evaluated. The thermoreversible fluid-to-gel transition of the colloidal gels allowed easy cell seeding when the gels were in their 
fluid state and good cell encapsulation within the colloidal gel matrix upon heating to $37^{\circ} \mathrm{C}$. Incubation of cells within the colloidal gels proceeded without disruption of the gel structure. The surface properties of the microparticles were likely to be dominated by the presence of the PDEGMA corona, which exhibited temperatureinduced changes in bound water. Consequently, above its coil-toglobule transition temperature the microparticle surfaces lost steric stabilisation from extended hydrated polymer chains and became more hydrophobic. In turn this reduced barriers to cell-particle attachment, allowing cells to adhere to the gel and proliferate. On reduction of the suspension temperature to below the expected lower critical solution temperature of PDEGMA $\left(<25^{\circ} \mathrm{C}\right)$, the polymer chains became hydrated and chain-extended, resulting in cell detachment from the microparticle surfaces. This phenomenon of thermoreversible bioadhesion hasbeen observed previously with grafted PEGMA polymers on various substrates, ${ }^{41-46}$

Presto Blue viability assays with $3 T 3$ fibroblasts cultured within the prepared colloidal gel showed that the cells proliferated and remained viable with significant increases in cell number over time from $1.07 \times 10^{5}$ cells on day 1 to $2.9 \times 10^{5}$ on day 3 and $4.16 \times 10^{5}$ on day 6 of culture (figure 4 a). Also, mesenchymal stem cells (MSCs) increased in number in the gels from $1.05 \times 10^{5}$ cells on day 1 to $2.5 \times 10^{5}$ on day 5 and $3.85 \times 10^{5}$ on day 10 . From comparison of cells grown within the colloidal gel (3D) with cells grown in tissue culture flasks (2D), it was apparent (Figure S8 ESI) that the proliferation capacity on the 2D surface was lower than in the 3D gel. The total number of cells from the 3D matrices was higher compared to that for cells grown on the 2D plastic surfaces. For instance, for the same cell seeding density on the 2D culture flask, the total numbers of 3T3 cells were $2.4 \times 10^{5}$ and $3.75 \times 10^{5}$ at day 3 and day 6 , respectively, compared to $2.9 \times 10^{5}$ on day 3 and $4.16 \times 10^{5}$ for the $3 \mathrm{D}$ matrices. Similarly, the total MSC numbers were $2.1 \times 10^{5}$ and $3.41 \times 10^{5}$ at day 5 and day 10 , respectively, again lower than those in the colloidal gels.
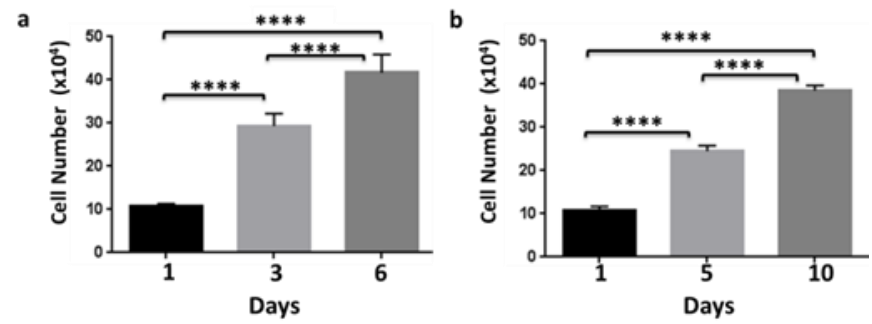

Figure 4: Proliferation of (a) 3T3 cells and (b) MSCs cultured within the particle gels, respectively. Cell numbers were measured by the Prestoblue viability asay on day 1,3 and 6 for 3 T 3 cells and on day 1, 5 and 10 for MSCs.

Confocal and fluorescent microscopy (Figure 5 and S9 ESI, respectively) of $3 \mathrm{~T} 3$ cells genetically modified to express red fluorescent protein (RFP-3T3) demonstrated that cells adhered, remained viable, proliferated and retained their normal morphology after repeat culture and release cycles.

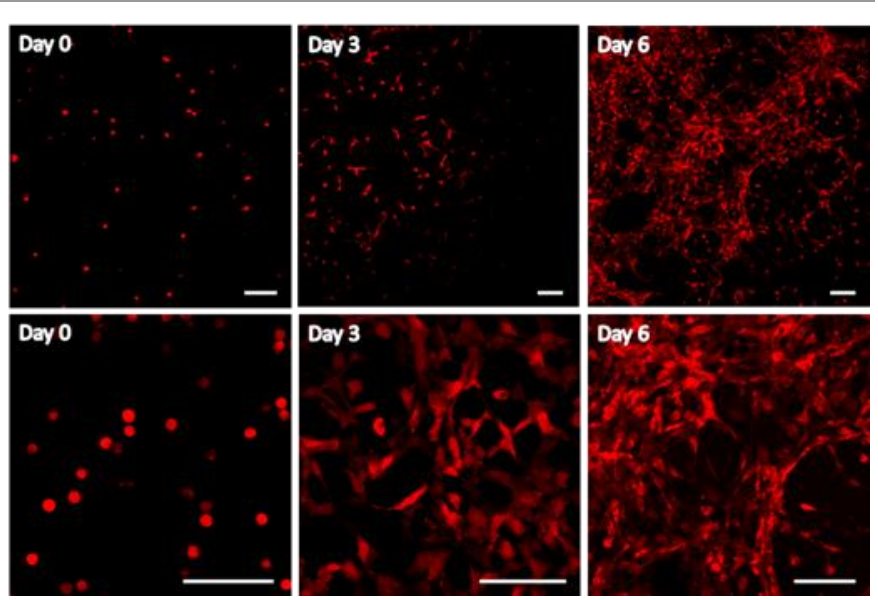

Figure 5: Confocal Microscopy Images of RFP-3T3 cells in 3D scaffold on day 0, 3, and 6 post-seeding. Images were taken at low (10X) and high (40X) magnification for the same samples. Scale bars - $100 \mu \mathrm{m}$.

Live/Dead cell assays (Figure S10 ESI) in which viable and dead cells were stained with calcein AM (green) and ethidium homodimer-1 (red), respectively confirmed that cells grown within the colloidal gel were found to be viable (green), with the number of dead cells (red) comprising $>3 \%$ of the sample.

\section{Cell recovery and passaging}

The cytocompatibility and applicability of the colloidal gels for in vitro cell proliferation were further explored in terms of the efficiency of cell recovery after expansion and to examine the possibility for multiple sequential cell passaging experiments without using trypsin.

Following three cycles of separation, the efficiency of cell recovery was quantified using the PrestoBlue viability assay and the total cell recoveries were recorded at days 3 and 6 for 3T3 cells and day 5 and 10 for MSC. The results showed a high recovery of 3 T3 cells from the colloidal gel of $93.5 \%$ and $95.2 \%$ total cell content at day 3 and 6 , respectively. The recovery efficiencies for MSCs were $94.4 \%$ and $92.8 \%$ of cells at day 5 and 10 , respectively.

The ability to support continuous cell proliferation and to carry out repeat passaging of cells with single batches of colloidal gel particles was also tested. Cells were grown in the gel matrices and magnetic separations were used as before to separate cells from the particles. The separated particles were then re-used to culture new batches of cells. The relevant data are shown in Figure 6; these results indicate that single batches of colloidal gel were suitable for multiple cycles of cell growth and separation. These experiments were performed with cooling cycles at $10{ }^{\circ} \mathrm{C}$ to effect the most rapid separations (typically 4 minutes per cycle). However, the same experiments could be performed with cooling cycles at room temperature with no loss in numbers of cells recovered. It should be noted that the overall numbers of separated and reloaded cells were less than 
when cells were continuously proliferated without separation. This was most likely due to incomplete separation of all cells at day 3 and 6 for 3T3 cells and at day 5 and 10 for MSC. The loss in efficiency was no more than $10 \%$ after the third cycle, and no attempts were made to optimise the separation steps at this stage beyond proof-of-concept. It is likely that cell yields could be improved if necessary by slower cell/particle concentration steps and reduced flow rates in the magnetic separation step to avoid excessive co-aggregation of cells and particles.
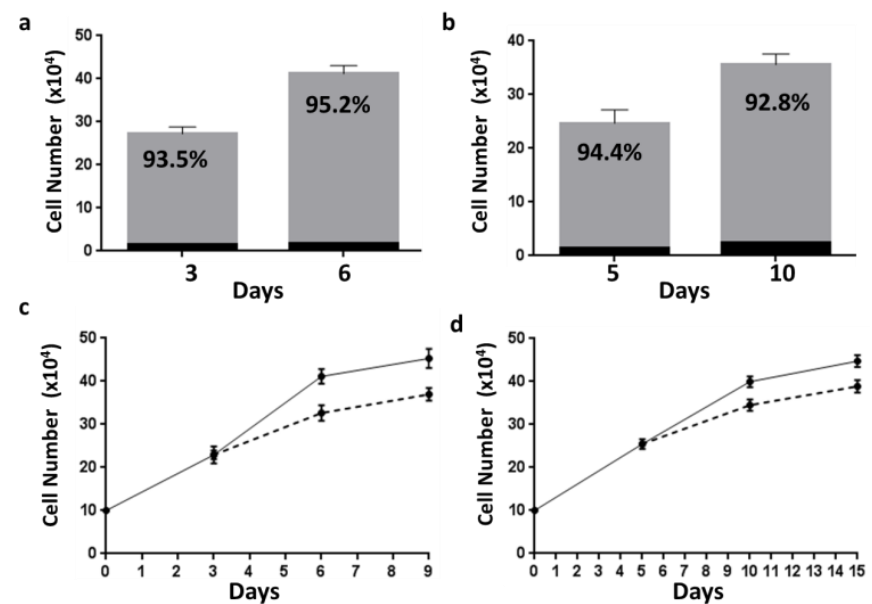

Figure 6: (a) and (b) the efficiency of the recovery of proliferated 3T3 and MSC within the colloidal gel by magnetic separation, respectively. (c) and (d) are 3T3 and MSC cell proliferation within the colloidal gel over time, respectively. straight lines respresent continues cell proliferation without passages and dashed lines represent cell proliferation when passaged two times (on day 3 and 6 for $3 T 3$ and on day 5 ad 10 for MSC).

\section{Conclusions}

In conclusion, we have synthesised a new thermo and magnetic responsive colloidal gel suitable for growth and support of cells for tissue culture applications. The materials have the advantage over previous colloidal gel systems in that the PDEGMA thermosensitive polymeric stabilizer is covalently grafted to the surface. This in turn allows these materials to be used repeatedly for successive rounds of cell culture. The synthetic method was easily adaptable to incorporate magnetite nanoparticles into the thermoresponsive microparticles with retention of magnetic properties. Aqueous suspensions of these magnetothermally responsive microparticles exhibited fast thermoreversible self-association behaviour combined with a simple magnetic separation stage. Two different cell types, 3T3 and MSCs, were grown with retention of cell morphology in the gel matrices, suggesting good cytocompatibility, albeit in laboratory cell lines rather than primary cells, of the new materials. Multiple cell culture and combined cooling/magnetic separation stages without trypsin were also possible, and the same batches of particles could be used for repeat cycles of cell growth and separation. Overall these results suggest the potential of the prepared particle gels as 3D scaffolds for in vitro expansion of cells and applications in regenerative medicine and cell therapies.

\section{Acknowledgements}

This research was supported by the Engineering and Physical Sciences Research Council (EPSRC: Grants EP/H005625/1, EP/D501849/1 and EP/H028277/1) and a Kurdistan Government Scholarship to SB. We also thank Dr Mahmood Soleman, Dr Aram Saeed, Mr Paul Cooling, Christine GraingerBoultby, Gemma Bray and Dr Omer Qutachi for experimental support and helpful discussions.

\section{Notes and references}

a- School of Pharmacy, University of Nottingham, Nottingham, NG7 2RD, UK. E-mail: cameron.alexander@nottingham.ac.uk, Fax: +44 (0)115 8466296; Tel: +44 (0) 115467678.

b- School of Materials, University of Manchester, Manchester, M13 9PL, brian.saunders@manchester.ac.uk.

Electronic Supplementary Information (ESI) available: [details of any supplementary information available should be included here]. See DOI: $10.1039 / \mathrm{b} 000000 \mathrm{x} /$

1. P. M. Kharkar, K. L. Kiick and A. M. Kloxin, Chem Soc Rev, 2013, 42, 7335-7372.

2. E. S. Place, J. H. George, C. K. Williams and M. M. Stevens, Chem Soc Rev, 2009, 38, 1139-1151.

3. C. Yang, M. W. Tibbitt, L. Basta and K. S. Anseth, Nature Mater, 2014, 13, 645-652.

4. H. Vihola, A. K. Marttila, J. S. Pakkanen, M. Andersson, A. Laukkanen, A. M. Kaukonen, H. Tenhu and J. Hirvonen, Int J Pharm, 2007, 343, 238-246.

5. Y. S. Pek, A. C. A. Wan, A. Shekaran, L. Zhuo and J. Y. Ying, Nature Nanotec, 2008, 3, 671-675.

6. M. Fraylich, W. X. Wang, K. Shakesheff, C. Alexander and B. Saunders, Langmuir, 2008, 24, 7761-7768.

7. M. R. Fraylich, R. Liu, S. M. Richardson, P. Baird, J. Hoyland, A. J. Freemont, C. Alexander, K. Shakesheff, F. Cellesi and B. R. Saunders, J Coll Interf Sci, 2010, 344, 61-69.

8. R. Umegaki, M. Kino-oka and M. Taya, Biochem Eng J, 2004, 17, 4955.

9. H. L. Huang, H. W. Hsing, T. C. Lai, Y. W. Chen, T. R. Lee, H. T. Chan, P. C. Lyu, C. L. Wu, Y. C. Lu, S. T. Lin, C. W. Lin, C. H. Lai, H. T. Chang, H. C. Chou and H. L. Chan, J Biomed Sci, 2010, 17.

10. A. Garg, D. D. Houlihan, V. Aldridge, S. Suresh, K. K. Li, A. L. King, R. Sutaria, J. Fear, R. H. Bhogal, P. F. Lalor and P. N. Newsome, Cytotherapy, 2014, 16, 545-559.

11. S. Rimmer, A. N. M. Ramli and S. Lefevre, Polymer, 1996, 37, 41354139.

12. Z. F. Li and T. Ngai, Langmuir, 2010, 26, 5088-5092.

13. S. Ramakrishnan and C. F. Zukoski, Langmuir, 2006, 22, 7833-7842.

14. A. Elaissari, Prog Coll Pol Sci S, 2006, 133, 9-14.

15. R. C. Al Ghanami, B. R. Saunders, C. Bosquillon, K. M. Shakesheff and C. Alexander, Soft Matter, 2010, 6, 5037-5044.

16. Q. Wang, L. M. Wang, M. S. Detamore and C. Berkland, Adv Mater, 2008, 20, 236-+. 
17. W. X. Wang, H. Liang, R. C. Al Ghanami, L. Hamilton, M. Fraylich, K. M. Shakesheff, B. Saunders and C. Alexander, Adv Mater, 2009, 21, 1809-+.

18. A. Saeed, N. Francini, L. White, J. Dixon, T. Gould, H. Rashidi, R. C. Al Ghanami, V. Hruschka, H. Redl, B. R. Saunders, C. Alexander and K. M. Shakesheff, Adv Mater, 2015, 27, $662-$ 668.

19. N. N. Shahidan, C. Alexander, K. M. Shakesheff and B. R. Saunders, J Coll Interf Sci, 2013, 396, 187-196.

20. K. M. Shakesheff, C. Evora, I. Soriano and R. Langer, J Coll Interf Sci, 1997, 185, 538-547.

21. J. S. Shay, S. R. Raghavan and S. A. Khan, J Rheol, 2001, 45, $913-$ 927.

22. D. R. Breed, R. Thibault, F. Xie, Q. Wang, C. J. Hawker and D. J. Pine, Langmuir, 2009, 25, 4370-4376.

23. M. Seeber, B. Zdyrko, R. Burtovvy, T. Andrukh, C. C. Tsai, J. R. Owens, K. G. Kornev and I. Luzinov, Soft Matter, 2011, 7, 9962-9971.

24. B. Karagoz, G. Bayramoglu, B. Altintas, N. Bicak and M. Y. Arica, Ind Eng Chem Res, 2010, 49, 9655-9665.

25. M. N. Zhao, G. W. Zhou, L. Zhang, X. Y. Li, T. D. Li and F. F. Liu, Soft Matter, 2014, 10, 1110-1120.

26. N. Bicak, M. Gazi, G. Galli and E. Chiellini, J Polym Sci Polym Chem, 2006, 44, 6708-6716.

27. A. Mizutani, K. Nagase, A. Kikuchi, H. Kanazawa, Y. Akiyama, J. Kobayashi, M. Annaka and T. Okano, J Chromatogr A, 2010, 1217, 5978-5985.

28. M. Kaupp, T. Tischer, A. F. Hirschbiel, A. P. Vogt, U. Geckle, V. Trouillet, T. Hofe, M. H. Stenzel and C. Barner-Kowollik, Macromolecules, 2013, 46, 6858-6872.

29. C. Chevigny, D. Gigmes, D. Bertin, J. Jestin and F. Boue, Soft Matter, 2009, 5, 3741-3753.

30. Y. Kim, K. S. Choi, J. Y. Pyun, B. T. Choi and S. J. Ko, Lect Notes Comput Sc, 2003, 2667, 957-966.

31. K. Min, J. H. Hu, C. C. Wang and A. Elaissari, J Polym Sci Polym Chem, 2002, 40, 892-900.

32. A. Bayraktar, B. Saracoglu, C. Golgelioglu and A. Tuncel, J Coll Interf Sci, 2012, 365, 63-71.

33. J. F. Lutz, O. Akdemir and A. Hoth, J Am Chem Soc, 2006, 128, 1304613047.

34. Z. B. Hu, T. Cai and C. L. Chi, Soft Matter, 2010, 6, 2115-2123.

35. A. Tamura, J. Kobayashi, M. Yamato and T. Okano, Biomaterials, 2012, 33, 3803-3812.

36. A. S. Wadajkar, S. Santimano, L. Tang and K. T. Nguyen, Biomaterials, 2014, 35, 654-663.

37. M. Rahimi, A. Wadajkar, K. Subramanian, M. Yousef, W. Cui, J.-T. Hsieh and K. T. Nguyen, Nanomed Nanotech Biol Med, 2010, 6, 672-680.

38. D. Maity and D. C. Agrawal, J Magn Magn Mater, 2007, 308, 46-55.

39. M. C. Mascolo, Y. B. Pei and T. A. Ring, Materials, 2013, 6, 55495567.

40. J. E. Dixon, E. Dick, D. Rajamohan, K. M. Shakesheff and C. Denning, Mol Ther, 2011, 19, 1695-1703.

41. A. Dworak, A. Utrata-Wesolek, D. Szweda, A. Kowalczuk, B. Trzebicka, J. Aniol, A. L. Sieron, A. Klama-Baryla and M. Kawecki, Acs Appl Mater Inter, 2013, 5, 2197-2207.
42. S. Dey, B. Kellam, M. R. Alexander, C. Alexander and F. R. A. J. Rose, J Mater Chem, 2011, 21, 6883-6890.

43. M. Mertoglu, S. Garnier, A. Laschewsky, K. Skrabania and J. Storsberg, Polymer, 2005, 46, 7726-7740.

44. A. A. Brown, N. S. Khan, L. Steinbock and W. T. S. Huck, Eur Polym $J, 2005$, 41, 1757-1765.

45. E. Wischerhoff, K. Uhlig, A. Lankenau, H. G. Borner, A. Laschewsky, C. Duschl and J. F. Lutz, Angew Chem Int Edit, 2008, 47, 56665668.

46. S. Kessel, S. Schmidt, R. Muller, E. Wischerhoff, A. Laschewsky, J. F. Lutz, K. Uhlig, A. Lankenau, C. Duschl and A. Fery, Langmuir, 2010, 26, 3462-3467. 